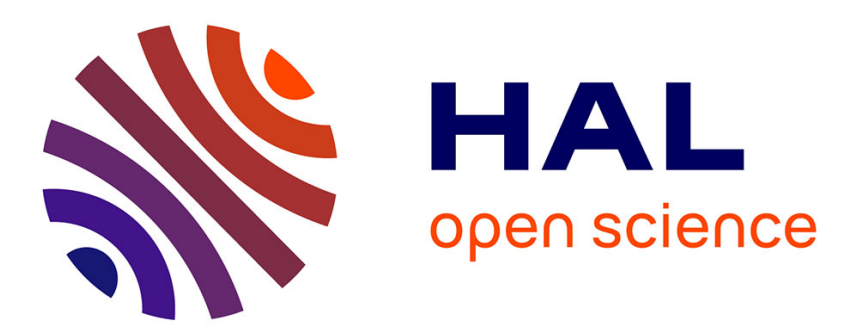

\title{
Influence of the dry woven fabrics meso-structure on fabric/fabric contact behaviour
}

Samir Allaoui, Gilles Hivet, Audrey Wendling, Pierre Ouagne, Damien Soulat

\section{To cite this version:}

Samir Allaoui, Gilles Hivet, Audrey Wendling, Pierre Ouagne, Damien Soulat. Influence of the dry woven fabrics meso-structure on fabric/fabric contact behaviour. Journal of Composite Materials, 2012, 46 (6), pp.627-639. 10.1177/0021998311424627 . hal-00772299

\section{HAL Id: hal-00772299 \\ https://hal.science/hal-00772299}

Submitted on 7 Feb 2013

HAL is a multi-disciplinary open access archive for the deposit and dissemination of scientific research documents, whether they are published or not. The documents may come from teaching and research institutions in France or abroad, or from public or private research centers.
L'archive ouverte pluridisciplinaire HAL, est destinée au dépôt et à la diffusion de documents scientifiques de niveau recherche, publiés ou non, émanant des établissements d'enseignement et de recherche français ou étrangers, des laboratoires publics ou privés. 


\title{
INFLUENCE OF THE DRY WOVEN FABRICS MESO-STRUCTURE ON FABRIC/FABRIC CONTACT BEHAVIOUR
}

\author{
S. Allaoui*, G. Hivet, A.Wendling, P. Ouagne, D.Soulat
}

Laboratoire PRISME, UPRES EA 4229, Université d'Orléans, Polytech'Orléans, 8 rue Léonard de Vinci 45072 Orléans Cedex 2, France.

* Corresponding author: E-mail: samir.allaoui@univ-orleans.fr; Phone: +33(0)238494376; Fax: +33(0)238417329

\begin{abstract}
The first stage of the RTM process concerns the preforming of the part. During the preforming of multilayered reinforcements, frictions between the plies occur. An experimental device designed to analyse the ply/ply, ply/tool and yarn/yarn frictions has been set up. Specific contact behaviour for ply/ply friction is directly related to shocks taking place between overhanging yarns of each samples. Within the signal, two particular periods can be exhibited. This work shows for four different architecture woven fabrics that the two periods are directly related to the meso architecture of the studied woven fabrics and more precisely to the characteristics of the fabric unit cell. The friction response appears to be very sensitive to the relative positioning and orientation of the samples. It can also lead to manufacturing defaults such as unweaving or wrinkles. Up to now, finite element codes predicting the forming behaviour of woven reinforcement fabrics do not take into account this friction coefficient evolution to model accurately the process. This point should therefore be addressed in future works on this topic with the view to optimise the multi-ply forming of composite parts.
\end{abstract}

KEYWORDS: Fabric, Woven reinforcement, Friction, RTM, Contact. 


\section{INTRODUCTION}

The market demand for fibre reinforced composites in various industries and especially in the transportation area is increasing. Processes of the LCM (Liquid Composite Moulding) family such as RTM (Resin Transfer Moulding) can be considered to elaborate lighter complex shapes parts. The first step of the process consists in draping a dry preform before injection of the liquid resin. The mechanisms taking place during the delicate preforming stage are complex and very different than the ones occurring during the stamping of metallic sheets. These mechanisms are far from being fully understood [1].

Many methods have been proposed recently to achieve representative sheet forming simulations for one layer of dry or thermoplastic fabric, with different approaches [2-5]. Several key entry parameters for the simulation models need to be determined experimentally. The mechanical properties of a single layer of different types of woven fabric reinforcement plies have been widely studied [6-11]. In addition to the reinforcement properties, the fabric/tool contacts and, for those dealing with multi-ply forming, the fabric/fabric contact has to be studied and modelled. The tool/fabric contact and to a lower extend the yarn/yarn contact have been investigated by different authors for carbon fibre reinforced thermoplastics or dry fabrics [12-15].

The numerical studies carried out to simulate multi-layer forming of dry fabrics use an approximate ply/ply friction coefficient not dependant on the yarns angle [5] whereas preliminary forming test conducted on a stack of reinforcement confirmed the significant influence of the relative positioning between dry plies [16] and therefore contact between layers. This phenomenon was also observed for thermoplastic preimpregnated reinforcements. However, the friction behaviour taking place during the 
forming of CFRTP is mainly a viscous friction due to the resin film between the layers. Consequently, the models based on the fact that the viscous interlayer plays a major role in the inter-ply and tool-ply slip $[2,19,20]$ cannot be used to quantify and analyse the friction between dry fabrics as the fabric mesostructure should play a much more significant role in the contact behaviour.

Studies investigating dry fabric frictions can be found in the textile scientific community, [21-26] and are among the most relevant over the last past years. However, the yarns in terms of mechanical properties and geometry are different from the ones used in composite reinforcements. Therefore, a direct use of the textiles results seems difficult, and a dedicated study concerning composite reinforcement is necessary.

The goal of this paper is then to propose an analysis of the contact behaviour between two layers of different dry technical fabrics using a specific device $([27,28]$, Figure 1) specifically developed in the lab in order to understand, optimize and model the first preforming stage of the RTM process. After a brief reminding of the device principles, the contacts mechanism involved and the specific aspect of the tangential force, results are pointed out. The influence of parameters such as the relative angle between the two layers, and type of patterns of dry fabric forming will be presented. This will also attest of the potentiality of the device, to perform further studies.

\section{MATERIALS TESTED}

Four different woven fabrics with different architectures have been used for this experimental study (Figure 2). Two glass plain weave fabrics, a carbon twill weave and a carbon interlock. The first glass plain weave is a $0.6 \mathrm{~mm}$ thickness Tissa+ glass plain weave with an areal weight of about $740 \mathrm{~g} / \mathrm{m}^{2}$. The yarns have widths of a $2.1 \mathrm{~mm}$ and 
an average spacing between yarns of $2.3 \mathrm{~mm}$. The second material tested in this is work is a 0.75 thickness "balanced" glass plain weave with an areal weight of about $504 \mathrm{~g} / \mathrm{m}^{2}$. It has a $3.75 \mathrm{~mm}$ width yarns, $5 \mathrm{~mm}$ average spacing between weft yarns and $4.5 \mathrm{~mm}$ spacing between warp yarns. The carbon twill weave is the Hexcel G986 ${ }^{\circledR}$. It has an areal weight of $285 \mathrm{~g} / \mathrm{m}^{2}$ and is constituted of HTA $51316 \mathrm{~K}$ yarns. The Average yarn width is $2.68 \mathrm{~mm}(\sim 2.6 \mathrm{~mm}$ for warp, $\sim 2.8 \mathrm{~mm}$ for weft $)$. The average yarns spacing is $2.92 \mathrm{~mm}(\sim 2.91 \mathrm{~mm}$ for warp, $\sim 2.93$ for weft $)$. The interlock fabric is an powdered Hexcel G1151 ${ }^{\circledR}$. It has an areal weight of $630 \mathrm{~g} / \mathrm{m}^{2}$ and is constituted by T300JB $6 \mathrm{~K}$ yarns. The nominal construction is $7.5 \mathrm{yarns} / \mathrm{cm}$ for warp and 7.4 yarns $/ \mathrm{cm}$ for weft. The $\mathrm{G} 1151^{\circledR}$ unit cell consists in 6 warp yarns and 15 weft yarns, the weft yarns being distributed on 3 levels (Figure 2)[30]. In situ average yarn width is about $2 \mathrm{~mm}$ for warp and $3 \mathrm{~mm}$ for weft.

\section{DESCRIPTION OF THE DEVICE AND PRELIMINARY RESULTS}

\subsection{DESCRIPTION OF THE DEVICE}

When considering experimental investigations on dry fabrics frictions, various mesoscopic heterogeneities with very different unit cell sizes and anisotropy should be considered. This suggests that specific experimental equipments should be considered to take into account these specifications. A specific experimental device dedicated to this task has consequently been designed in the lab and presented in Figure 1 [27, 28]. The classical principle consisting in two plane surfaces sliding one on each other is considered to be the most promising for this study. This principle has beside been chosen by most of the teams working on fabric friction [12, 13, 22, 25, 29]. This experimental principle is furthermore directly related to the interply sliding during 
forming. The bottom sample $(60 \mathrm{~cm}$ long and $9 \mathrm{~cm}$ width) is fixed on steel plate. It is rigidly and accurately guided by a linear system in order to translate horizontally in a fixed direction. A motor and an electronic speed controller are used to impose the displacement with a speed variation from 0 to $100 \mathrm{~mm} / \mathrm{s}$. The top sample $(10 \mathrm{~cm}$ long and $8 \mathrm{~cm}$ width) is fixed on a steel plate which is linked to the load sensor. The lateral positioning of the upper sample is ensured by a linear joint. The load sensor is calibrated and used in the $0-20 \mathrm{~N}$ range in order to get fully acceptable $0.01 \mathrm{~N}$ accuracy. An acquisition system is used to record measurements. Details on the device design and validation can be found in [28].

\subsection{PRELIMINARY RESUlTS ON ONE COUPLE OF PLAIN WEAVE SAMPLES:}

Before going to a more extensive and accurate analysis of the fabric/fabric friction, let us remember the preliminary results and conclusions already presented in $[27,28]$ (Figure 3, Figure 4) for the fabrics presented on section 2. As it was expected, a specific contact behaviour was observed for dry reinforcement fabrics in comparison to non technical textiles (garments,...), yarn/yarn or fabric/metal (Figure 3). Particularly, variations of the contact tangential loads appeared to be very substantial while all the test parameters remained constant. It was consequently concluded that defining an average friction coefficient (about 0.39 in this case) would lead to a high amount of uncertainties in the mechanical analysis of these materials (Figure 3.b).

A more accurate analysis of the response enables us to distinguish three characteristic pseudo periods. The first one depicts the undulation of the local maximum values (Figure 3.a). Even if its value is not so easy to quantify, this first period can be approximately evaluated and is equal to about $\mathrm{T}=60 \mathrm{~s}$. Local minimum values are not submitted to the same type of undulation as the maximum values, and their magnitude is 
much smaller. A representative period does not appear so clearly, the lack of symmetry is noticeable. The second period is associated to the interval between two maximum load values when the response magnitude is the highest ( $6 \mathrm{~N}$, Figure 3.c). Its value is about $T_{B}=1 \mathrm{~s}$. The third one is the duration separating two maximum load values when the response magnitude is the lowest ( $\sim \mathrm{N}$, Figure 3.c).Its value is about $\mathrm{T}_{\mathrm{A}}=0.5 \mathrm{~s}$. These two latest periods also appeared to be repeatable (Figure 4).

These preliminary experiments have also pointed out a honing (effect classically observed in dry fabric testing) through cyclic experiments. It has been attributed both to fibres material abrasion but also to fibre reorganisation into the yarn [28]. Using the potentiality of the designed device and experiments at higher sampling frequencies, the goal of this paper is to analyse the origin of this particular behaviour and especially to point out the influence of the fabric meso-structure.

\section{INFLUENCE OF THE MESOSCOPIC ARCHITECTURE OF THE FABRIC: TESTS AT HIGHER SAMPLING FREQUENCY}

\subsection{PHYSICAL PHENOMENOLOGY- ANALYSIS OF PLAIN WEAVE RESULTS}

In order to analyze more accurately the signal variations, tests at a high sampling frequency $(333 \mathrm{~Hz})$ have been performed. As the total amount of recordable data points is limited (maximum 4000), only a part of the global sliding stroke can be covered $(6 \mathrm{~cm}$ with a $3 \mathrm{~ms}$ sampling rate at a displacement speed of the bottom sample of $5 \mathrm{~mm} / \mathrm{s}$ ). Consequently, different tests at different locations of the stroke have been performed in order to get results in the different zones of interest (zone A, zone B and transition zone in Figure 3). If a longer part of the sample needs to be covered, consecutive tests can be performed. Almost a continuous curve along the whole stroke can be obtained through 
this protocol. It is not completely continuous because for each test the time needed to reach the steady state requests to be considered (tempo $0.7 \mathrm{~s}$ in our case).

An example of results obtained through this protocol for two consecutive zones of the same sample is presented in Figure 5. Two different signals are clearly visible in Figure 5.a and b. Period and magnitude of them are globally constant. They can be accurately measured using these fine results, plotted in time units. The average value for each of them is: $T_{A}=0.46 \mathrm{~s}$ and $T_{B}=0.92 \mathrm{~s}$, with a standard deviation lower than $\pm 10 \%$ which is remarkable considering the fabrics structure. The transition zone (Figure5.c) consists in the progressive appearing and disappearing of an additional pick. Figure 6 gives the period value on the all stroke of the couple studied on Figure 5, expressed in length units. This curve points out very clearly the two different zones (A and B) previously observed and confirms the noticeable stability of the period inside each of them. A comparison between the measured length periods: $d_{A} \sim 2.3 \mathrm{~mm}$ and $d_{B} \sim 4.6 \mathrm{~mm}$ to the geometrical parameters of the fabric unit cell can be carried out. The distance between two consecutive yarns is $2.3 \mathrm{~mm}$. Thus the size of the unit cell (periodic geometry) is $4.6 \mathrm{~mm}$ for this plain weave. The characteristic periods values found in the friction test signal seem to be similar to the meso geometrical parameters of the fabric. This statement seems to confirm the influence of the fabric meso structure on the friction behaviour. Figure 7 presents an example of results obtained for different samples of the second Glass plain weave. The specific contact behaviour already shown in Figure 5 is also observed and the consistency between the period values and the fabric geometrical parameters is unquestionably confirmed as the values of the characteristic period are similar to the values of the space between two yarns and the elementary cell width as mentioned in Section 2. 
The influence of the meso geometrical structure of the fabric is easily understood through a simple geometrical analysis as illustrated in Figure 8. If the two samples are perfectly superimposed, the highest zone of the bottom layer encounters the lower zone of the upper sample. The contact consists in the superposition of yarn/yarn sliding friction and shocks between the transverse yarns of each sample, at each period of the unit cell, at the same time everywhere on the sample width (Figure 8.a). Consequently, high maximum friction values and variations are observed. This phenomenon is representative of zone B on Figure 3.c, Figure 5.b and Figure 7.b. This perfectly explains why the non technical fabrics with lower crimp and lower thickness yarns are submitted to variations with a lower magnitude. Shocks are more significant if the crimp is high and the yarns are thick. On the contrary if samples are shifted by half of a geometrical period (Figure 8.b), the highest zone of the bottom layer does not encounter the lowest zone of the top layer. In that configuration the contact period is lower and is repeated every half geometrical period. The impact between the yarns is also lower. As a consequence, lower maximum friction values, lower variations and a signal period corresponding to half of a unit cell can be observed. This corresponds to zone A in Figure 3.c, Figure 5.a and Figure 7.b. Between the two extreme shifts, the signal is a combination of these two contacts morphologies and the magnitude of the friction load depends on the actual shift between the bottom and the top sample.

On Figure 3, the signal indicates that the configuration corresponding to superimposed samples takes place as the period corresponding to a geometrical period is observable. On the same signal, lower period signal corresponding to shifted samples is also observable. This therefore suggests that a lateral shifting displacement during the test took place. This displacement is the consequence of the play in the linear joint (between 
the two plates and the roller) to ensure the preponderant planar positioning between the two samples and of the difficulty to align perfectly all the yarns of two samples of dry fabrics. This point is even more valid if the fabric cohesion is weak. Depending on the initial positioning of each sample (shift, angle), there can be more or less relative displacement between the two samples at different location along the samples. When the two samples is large enough and if the samples are very carefully positioned, only one characteristic period is observed along the stroke (Figure 4.b for instance).

\subsection{EXTENSION TO OTHER PATTERNS: TWILL WEAVE AND INTERLOCK RESULTS}

Results obtained for the interlock and twill weaves are presented in Figure 9 and Figure 10 respectively. The curves look very similar to the one presented in the previous section for the two glass plain weave fabrics. Periods values and magnitudes are obviously different because the meso architecture (pattern, crimp), the yarns constitution and geometry are different (width, thickness, density...). For the interlock weave, despite the complexity of the pattern and the yarns lower width and thickness, contact zones and transitions appear clearly (Figure 9). The two characteristic periods can be easily extracted: $d_{A} \sim 4 m m$ and $d_{B} \sim 8 \mathrm{~mm}$. These two values are here again fully consistent with the geometrical parameters of the fabric unit cell. The $8 \mathrm{~mm}$ period is related to the distance between two consecutive overhanging yarns (Figure 2.d) in the case of superimposed samples. Due to the complexity of the interlock pattern the $4 \mathrm{~mm}$ period (half of the first characteristic period) is much more difficult to analyze. Indeed, it was expected to observe for instance a $2.7 \mathrm{~mm}$ period corresponding to the distance between two neighbouring overhanging warp yarns (Figure 2.d). The lateral shift of the sample is accompanied by a more diffuse occurring of the shocks and by a strong decrease of the magnitude as observed for the glass plain weave fabric. 
Carbon twill results confirm and give complements to our analysis. The curve shape is as expected similar to the previously observed curves, but the variations magnitude is much lower than for the other couples of samples. By looking at the fabric geometry it has to be noticed that the small crimp, the low thickness of the yarns associated to a weaving process leading to a more balanced fabric. As a consequence, the weft yarn does not overhang much on the upper part of the warp yarns. Shock impacts are then reduced and magnitudes are lower. In this case also (even if the pattern is more simple than for the interlock weave), the contact chains are not as simple as in the case of plain weave fabrics. Indeed, contacts between the lowest zone of the upper sample and the highest zone of the lower sample concern various yarns and occur at different locations. However, the value of the characteristic period is of about $2.9 \mathrm{~mm}$ (Figure 10). This value can be associated to the unit cell length (Figure 2.c). The impact of the meso structure on the friction response is clear in this case also even if the complex contact chains and yarns profiles lead to a more confusing signal and lower variations magnitude.

As a matter of conclusion, even if the pattern is much more complex high variations are observed on the friction response. The highest amount of variation due to the shock between overhanging yarns of each sample leads to a periodic signal. This period is linked to the distance between two consecutive overhanging yarns that is for studied fabrics the unit cell length. The second pick due to the initial or progressive shifting of the two samples seems to be associated to half the unit cell length. This last point has to be investigated further. The weaving process parameters seem to influence the variations magnitude as shocks between weft and warp yarns are more intense when the weft yarns overhang greatly the warp yarns. This particularly happens when yarns 
are thicker and crimp is higher. This point will appear again and will be confirmed in the next section when dealing with the orientation of the two samples.

\section{INFLUENCE OF THE RELATIVE ORIENTATION OF THE TWO PLIES}

During forming, the plies can be stacked with various orientations. In addition, even if the orientation of the different plies is originally the same, in-ply shear corresponding to yarn reorientation regularly takes place. It is then crucial to study the evolution of the friction forces as a function of the ply angles. Plain weave fabrics are first addressed because of their pattern simplicity and more complex fabrics are also considered.

\subsection{PLAIN WEAVE FABRICS}

Seven relative ply/ply orientations have been tested for the first glass plain weave fabric with angle variation of $15^{\circ}$ from $0^{\circ} / 0^{\circ}$ to $0^{\circ} / 90^{\circ}$. The position $0^{\circ} / 0^{\circ}$ is considered as the reference position where the weft yarns of the two samples are oriented in the stroke direction. Results presenting the average friction coefficient and the standard deviation as a function of the relative orientation are shown in Figure 11.a. The sample positioning leads to high amounts of signal variations. The average value is not so easy to define especially for the $0^{\circ} / 0^{\circ}$ orientation. However, it has been calculated averaging the friction coefficient found for different tests.

When the angle between yarns increases a significant decrease of the average coefficient and of the standard deviation is observed. When the yarns are not parallel, contacts between yarns do not appear at the same time everywhere on the sample width. As a consequence a decrease of the friction load is expected. The theoretical minimum friction coefficient should be encountered for yarn angles of about $45^{\circ}$. However, as 
soon as the angle of $25^{\circ}$ the friction coefficient values remain constant for higher ply/ply angles and an asymptotic value is reached.

It is also interesting to notice, that although the weft yarns are parallels to the warp yarns when the orientation $0^{\circ} / 90^{\circ}$ is considered, the friction coefficient is lower than for the $0^{\circ} / 0^{\circ}$ orientation. This tends to confirm the impact of the weaving parameters. This plain weave fabric is therefore far from being balanced. As it has already been mentioned, warp yarns overhang widely weft yarns, thus warp shocks are more severe than weft shocks. If the fabric was balanced a symmetrical curve with respect to the $45^{\circ}$ ply/ply angle should be observed.

\subsection{Other Patterns}

The average friction coefficient and standard deviation are presented on Figure 11.b for the interlock weave. The influence of the orientation appears clearly. A decrease of the friction coefficient is observed below a ply/ply angle of $45^{\circ}$. Above $45^{\circ}$ angles the friction coefficient rises. The curve is almost symmetrical relatively to the $45^{\circ}$ angle. This is probably due to the fact that the overhanging of the warp yarns is almost the same as the overhanging of the weft yarns. The behaviour observed for the interlock is consequently close to the one of balanced fabric.

\subsection{CONCLUSION}

In relation to the influence of the meso architecture and the physical phenomena associated to the fabric/fabric friction behaviour, sample relative orientation has a significant influence on the friction response. The meso architecture is responsible for the high variations of the friction coefficient as a function of the ply orientations for different fabrics. 


\section{COMPARISON WITH YARN/YARN FRICTION}

The aim of this section is to evaluate the yarn/yarn friction coefficients of the studied materials and to compare them to the fabric/fabric ones. Yarn/yarn friction coefficients were measured using the device described in Section 3. Unweaving of the fabric was carried out to extract samples of yarns. Two types of experiments were conducted on parallel and on perpendicular yarns. Table 1 gathers the average values and standard deviation for three interesting cases: interlock fabrics yarns oriented $0 \% 0^{\circ}$ and $0^{\circ} / 90^{\circ}$, and first glass plain weave $0^{\circ} / 90^{\circ}$.

Results obtained are fully consistent with the theory previously developed. Indeed, shocks between yarns induce a sudden increase of the tangential response (Figure 12). To a lower extend, the end of the lateral impact between yarns tends to minimize the tangential loads. We could expect yarn/yarn $0^{\circ} / 0^{\circ}$ friction coefficient values to be similar to the average value of the fabric/fabric $0^{\circ} / 0^{\circ}$ friction coefficient. This comparison is presented in Figure 13.b. However, yarn/yarn $0^{\circ} / 0^{\circ}$ friction coefficient value is lower than the average value of the fabric/fabric $0 \% 0^{\circ}$ friction coefficient which proves that the increase of the maximum friction values due to the shocks is more important than the minimization taking place at the end of the shocks. Experiments conducted with $0^{\circ} / 90^{\circ}$ oriented yarns are not as concluding as in the $0^{\circ} / 0^{\circ}$ case because friction values and variations are lower and then much more submitted to discrepancies. Nevertheless it has to be noticed that the average fabric/fabric friction coefficient is closed to the yarn/yarn friction coefficient (Figure 14).

\section{CONCLUSION}

A specific device has been developed to characterise the contact behaviour 
between two layers of woven fabrics. The knowledge of the contact behaviour between layers of woven fabric is of particular importance when multiply forming is concerned. The device appeared to be well adapted to investigate fabric friction. The specific behaviour pointed out through preliminary results that is to say the substantial variations of the contact tangential loads, all the test parameters remaining constant can explained by shocks between overhanging yarns of each sample. It is consequently in complete relation with the fabric meso-structure. It has been demonstrated that periods of the friction response can be predicted. It is directly related to the length of the unit cell. Parameters influencing the magnitude of these variations are not quantified in this study. Nevertheless, whatever the type of pattern, both the weaving parameters and the yarn thickness and cohesion are undoubtedly of main importance. The friction response also appears to be very sensitive both to the relative positioning and orientation of the samples.

Variations of the friction load magnitude observed during fabric/fabric friction may be important and should be considered when trying to optimise multi ply forming. The evolution of the relative orientation between yarns of each ply may involve high variations of the tangential friction forces. It can also lead to manufacturing defaults such as unweaving or wrinkles. Up to now, finite element codes predicting the forming behaviour of woven reinforcement fabrics do not take into account this friction coefficient evolution to model accurately the process. This point should therefore be addressed in future works on this topic with the view to optimise the multi-ply forming of complex shape composite parts. 


\section{REFERENCES}

1. S. Hivet G., Allaoui S., Soulat D. Wendling A. Chatel (27 Jul-31 Jul 2009). Analysis of woven reinforcement preforming using an experimental approach. 17th International Conference on Composite Materials., Edinburgh International Convention Centre (EICC), Edinburgh, UK.

2. K. Vanclooster, S. Lomov, and I. Verpoest (2010). Simulation of multi-layered composites forming. International Journal of Material Forming, 3:695-698.

3. R.H.W. ten Thije, R. Akkerman, and J. Huétink. (2007). Large deformation simulation of anisotropic material using an updated lagrangian finite element method. Computer Methods in Applied Mechanics and Engineering, 196(3334):3141-3150.

4. G. Creech and A. Pickett (2006). Meso-modelling of non-crimp fabric composites for coupled drape and failure analysis. Journal of Materials Science, 41:67256736.

5. N. Hamila and P. Boisse (2007). A meso macro three node finite element for draping of textile composite preforms. Applied Composite Materials, 14:235-250.

6. S.V. Lomov and I. Verpoest (2006). Model of shear of woven fabric and parametric description of shear resistance of glass woven reinforcements. Composites Science and Technology, 66(7-8):919-933.

7. J. Launay, G. Hivet, A.V. Duong, and P. Boisse (2008). Experimental analysis of the influence of tensions on in plane shear behaviour of woven composite reinforcements. Composites Science and Technology, 68(2):506-515.

8. E. de Bilbao, G. Soulat, D. Launay, J. Hivet, and A. Gasser (2010). Experimental study of bending behaviour of reinforcements. Experimental Mechanics, 50(3):333-351.

9. J. Cao, R. Akkerman, P. Boisse, J. Chen, H.S. Cheng, E.F. de Graaf, J.L. Gorczyca, P. Harrison, G. Hivet, J. Launay, W. Lee, L. Liu, S.V. Lomov, A. Long, E. de Luycker, F. Morestin, J. Padvoiskis, X.Q. Peng, J. Sherwood, Tz. Stoilova, X.M. Tao, I. Verpoest, A. Willems, J. Wiggers, T.X. Yu, and B. Zhu (2008). Characterization of mechanical behavior of woven fabrics: Experimental methods and benchmark results. Composites Part A, 39(6):1037-1053.

10. Wiggers J. Harrison, P. and A.C. Long (2008). Normalisation of shear test data for rate-independent compressible fabrics. Journal of Composite Materials, 42(22):2315-2343.

11. P. Badel, E. Vidal-Sallé, and P. Boisse (2007). Computational determination of inplane shear mechanical behaviour of textile composite reinforcements. Computational Materials Science, 40(4):439-448.

12. R. H. W. ten Thije and R. Akkerman (2009). Design of an experimental setup to measure tool-ply and ply-ply friction in thermoplastic laminates. International Journal of Material Forming, 2(1):197-200.

13. Jennifer L. Gorczyca, James A. Sherwood, Lu Liu, and Julie Chen (2004). Modeling of friction and shear in thermostamping of composites - part I. Journal of Composite Materials, 38(21):1911-1929.

14. Lu Liu, Julie Chen, Jennifer L. Gorczyca, and James A. Sherwood (2004). Modeling of friction and shear in thermostamping of composites - part II. Journal 
of Composite Materials, 38(21):1931-1947.

15. Gilbert Lebrun, Martin N. Bureau, and Johanne Denault (2004). Thermoformingstamping of continuous glass fiber/polypropylene composites: Interlaminar and tool laminate shear properties. Journal of Thermoplastic Composite Materials, 17(2):137-165.

16. S. Allaoui, G. Hivet, A. Wendling D. Soulat S. Chatel (7-10 June, 2010). Experimental approach for optimizing dry fabric formability. the 14th European Conference on Composite Materials (ECCM 14), Budapest, Hungary, ID347ECCM14.

17. Mallon PJ. Murtagh AM, Monaghan MR. (1994). Investigation of the interply slip process in continuous fibre thermoplastic composites. In Proceedings of ICCM-9, Madrid, Spain, page 311-318.

18. K. Vanclooster, S. Van Goidsenhoven, S. Lomov, and I. Verpoest (2009). Optimizing the deepdrawing of multilayered woven fabric composites. International Journal of Material Forming, 2(1):153-156.

19. R. ten Thije, R. Akkerman, L. van der Meer, and M. Ubbink (2008). Tool-ply friction in thermoplastic composite forming. International Journal of Material Forming, 1(1):953-956.

20. Jennifer L. Gorczyca-Cole, James A. Sherwood, and Julie Chen (2007). A friction model for thermostamping commingled glass-polypropylene woven fabrics. Composites Part A: Applied Science and Manufacturing, 38(2):393 - 406.

21. J. O. Ajayi and H. M. Elder (1997). Fabric friction, handle, and compression. Journal of the Textile Institute, 88(3):232-241.

22. A. A. A. Jeddi, S. Shams, H. Nosraty, and A. Sarsharzadeh (2003). Relations between fabric structure and friction: Part i: Woven fabrics. Journal of the Textile Institute, 94(3):223-234.

23. USA B S Gupta, NCSU, editor. (2008). Friction in textile materials. Woodhead Publishing Limited.

24. Bhupender S. Gupta and Yehia E. El Mogahzy (1991). Friction in fibrous materials part i: Structural model. Textile Research Journal, 61(9):547-555.

25. Luis Virto and Arun Naik (2000). Frictional behavior of textile fabrics : Part II, dynamic response for sliding friction. Textile Research Journal, 70(3):256-260.

26. Mario Lima, Rosa M. Vasconcelos, Luis F Silva, and Joana Cunha (2009). Fabrics made from non-conventional blends: What can we expect from them related to frictional properties. Textile Research Journal, 79(4):337-342.

27. S. Allaoui, G Hivet, and J.L. Billoet (2009). Experimental analysis of the contact between layers of dry fabrics. International Journal of Material Forming, 2(1):209-212.

28. G. Hivet, S. Allaoui, B.T. CAM, P. Ouagne, and Soulat. Design and potentiality of an apparatus for measuring yarn/yarn and dry fabric/dry fabric friction. Experimental Mechanics, Submitted.

29. K. Vanclooster, S. Lomov, and I. Verpoest (2008). Investigation of interply shear in composite forming. International Journal of Material Forming, 1(1):957-960.

30. P. Badel, E. Vidal-sallé, E. Maire and P. Boisse (2008). Simulation and tomography analysis of textile composite reinforcement deformation at the mesoscopic scale. Composite Science and Technologie, 68(12):2433-2440. 


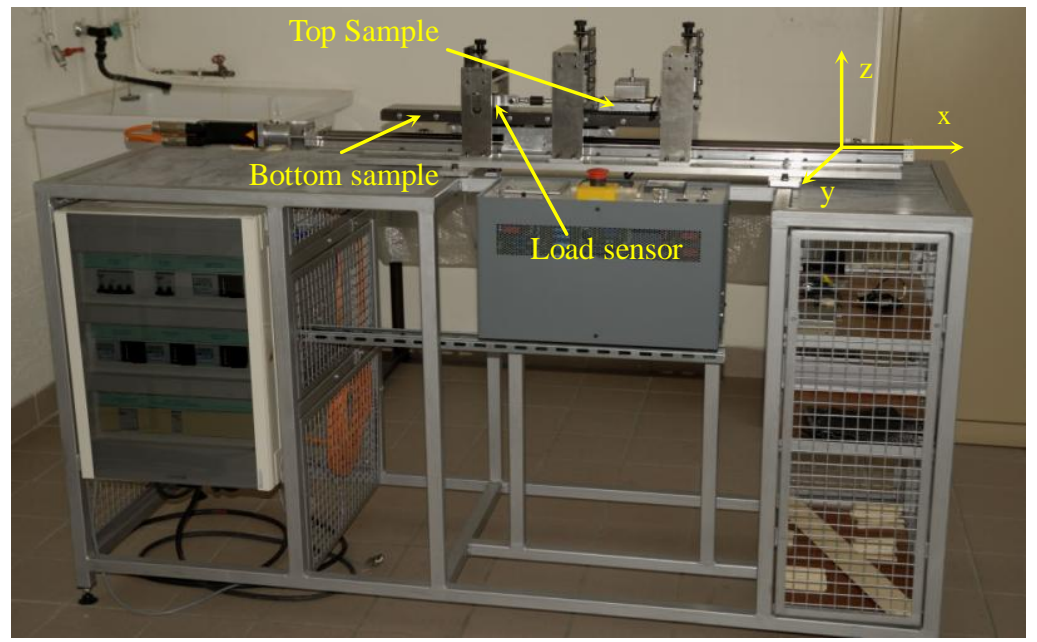

Figure 1 : External view of the friction device.

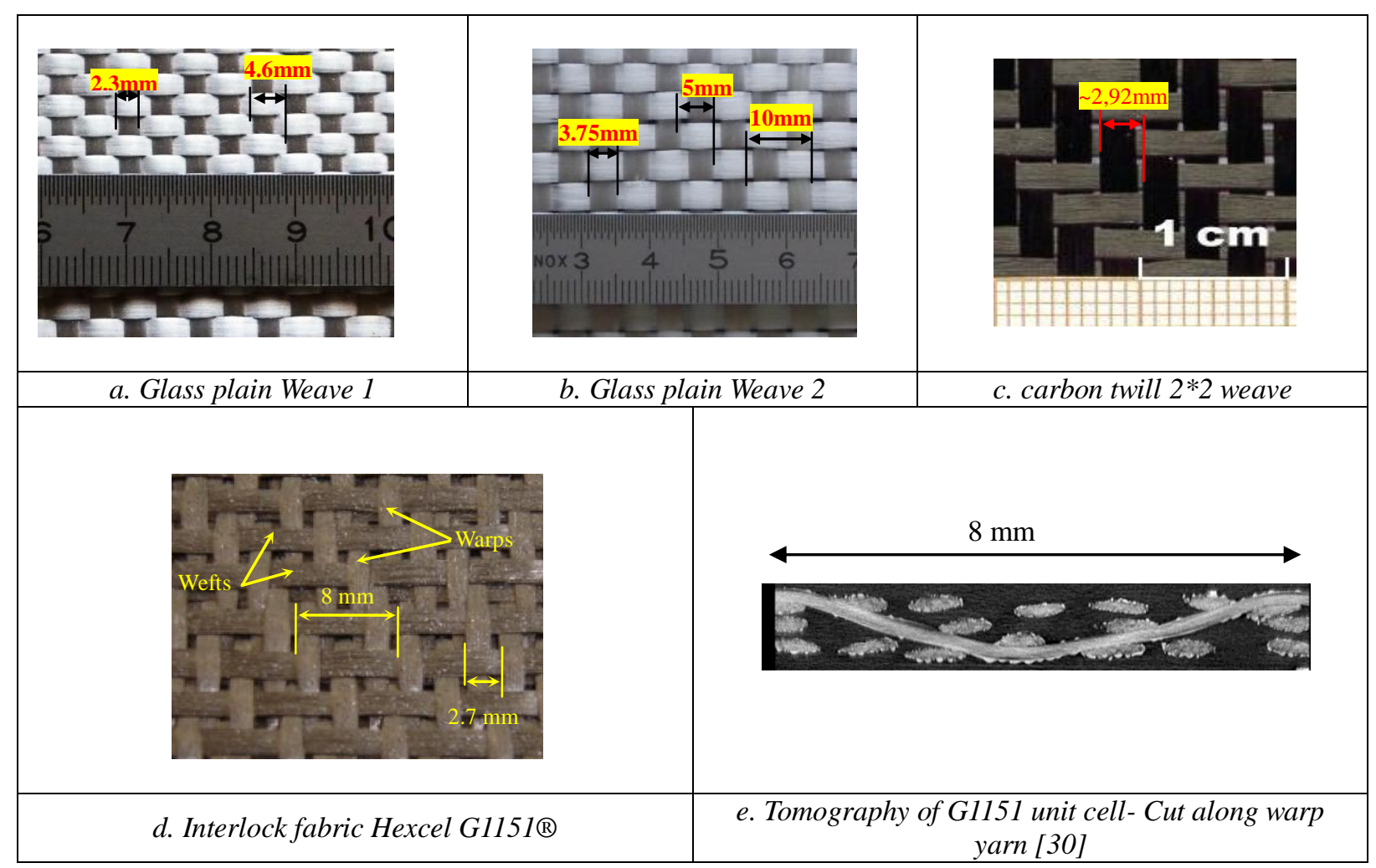

Figure 2 : Fabrics used for fabric/fabric friction. 


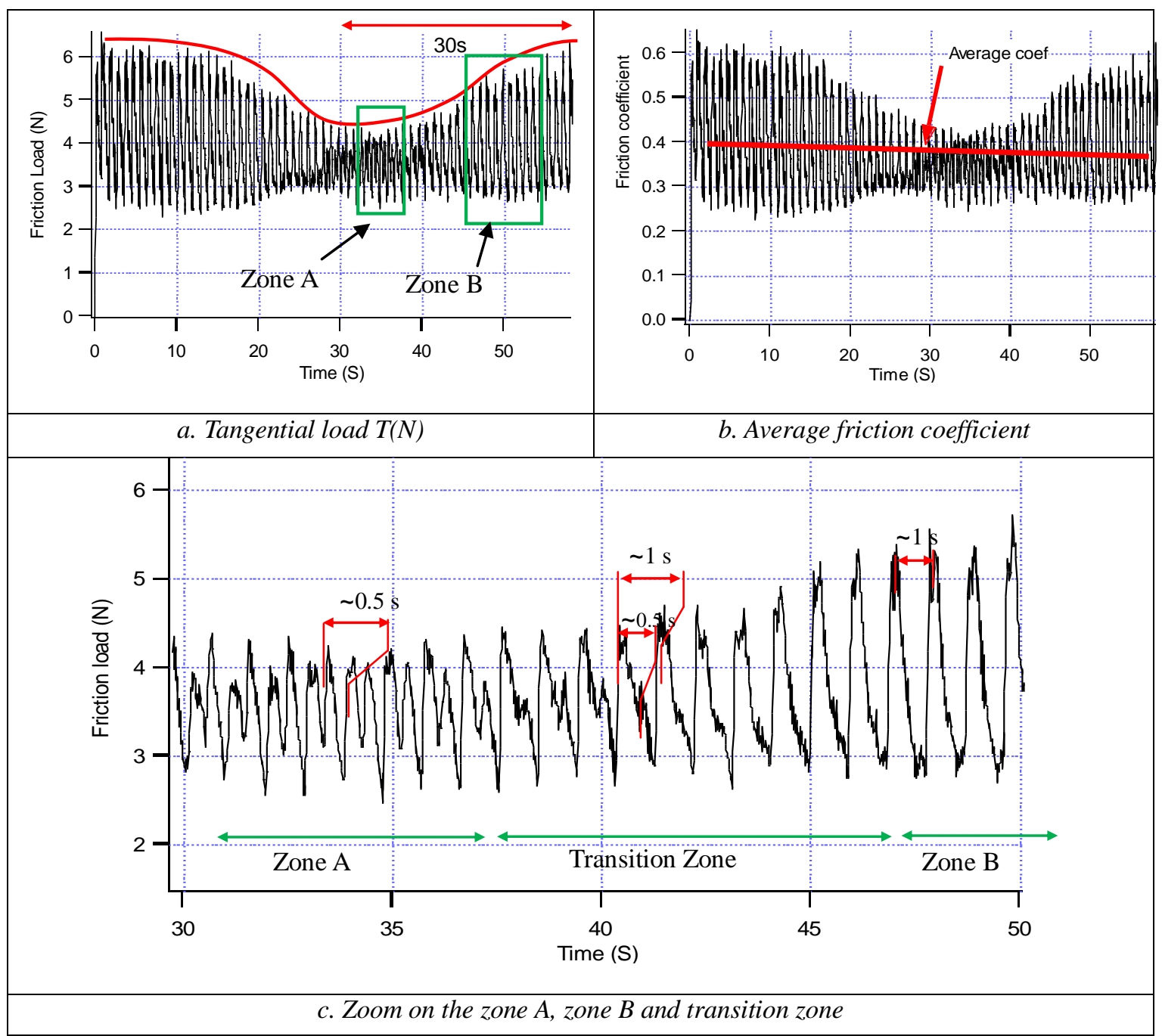

Figure 3 : Experimental results for the Glass plain weave $1, v=5 \mathrm{~mm} / \mathrm{s}, \mathrm{N}=10 \mathrm{~N}, 66 \mathrm{~Hz}$ sampling.

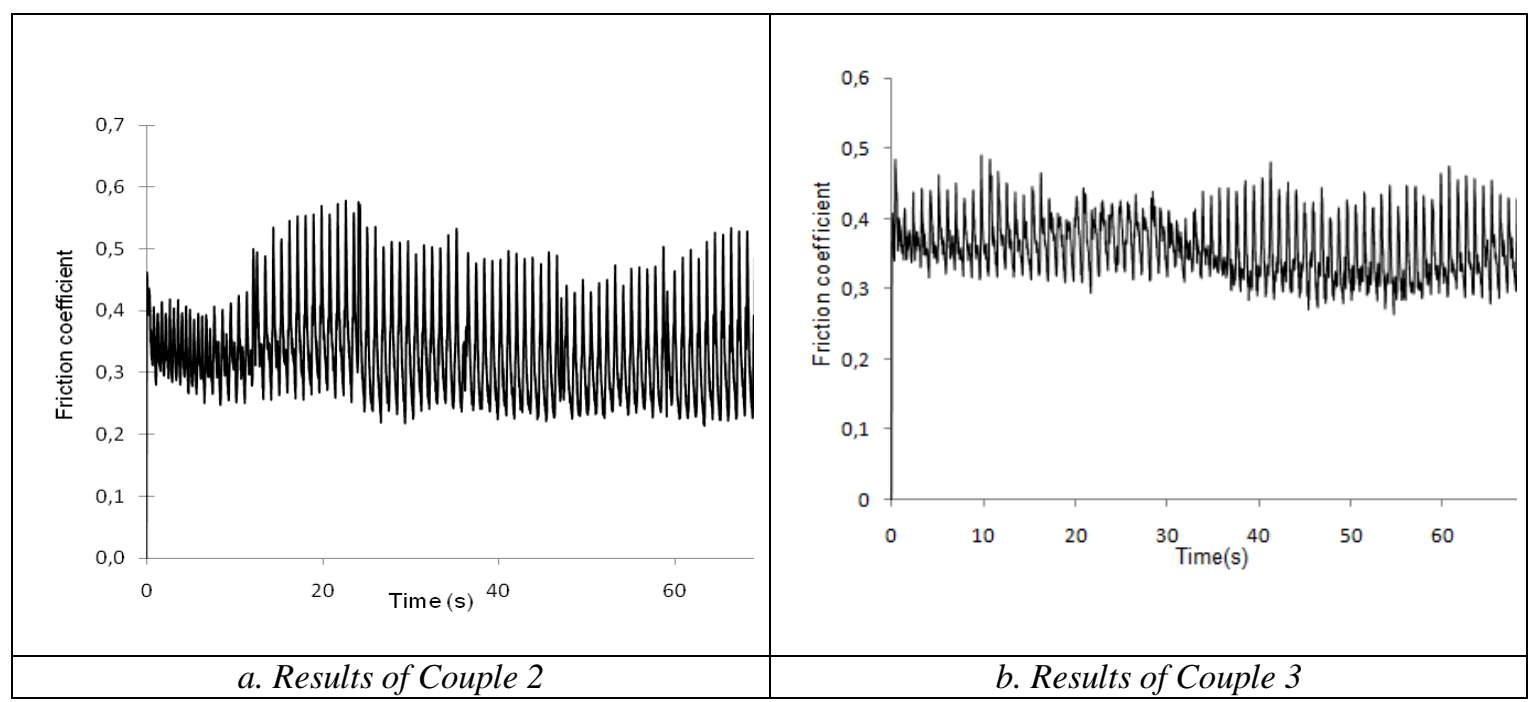


Figure 4 : Friction coefficient results for 2 other identical samples of the glass plain weave $1 \mathrm{v}=, 5 \mathrm{~mm} / \mathrm{s}$, $\mathrm{N}=10 \mathrm{~N}, 66 \mathrm{~Hz}$ sampling.

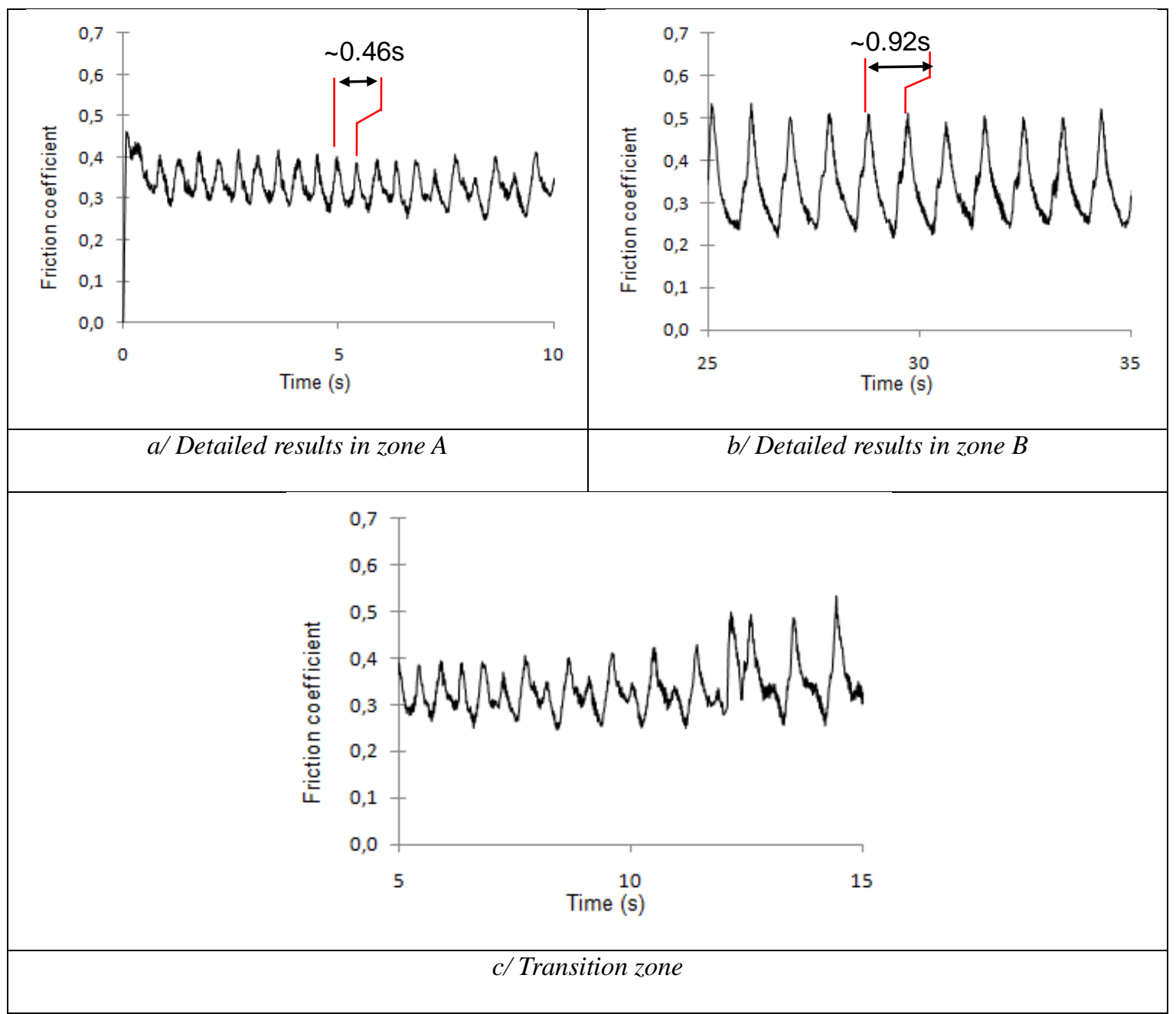

Figure 5 : Experimental results for the Glass plain weave1, v=5mm/s, N=10N, 333Hz sampling.

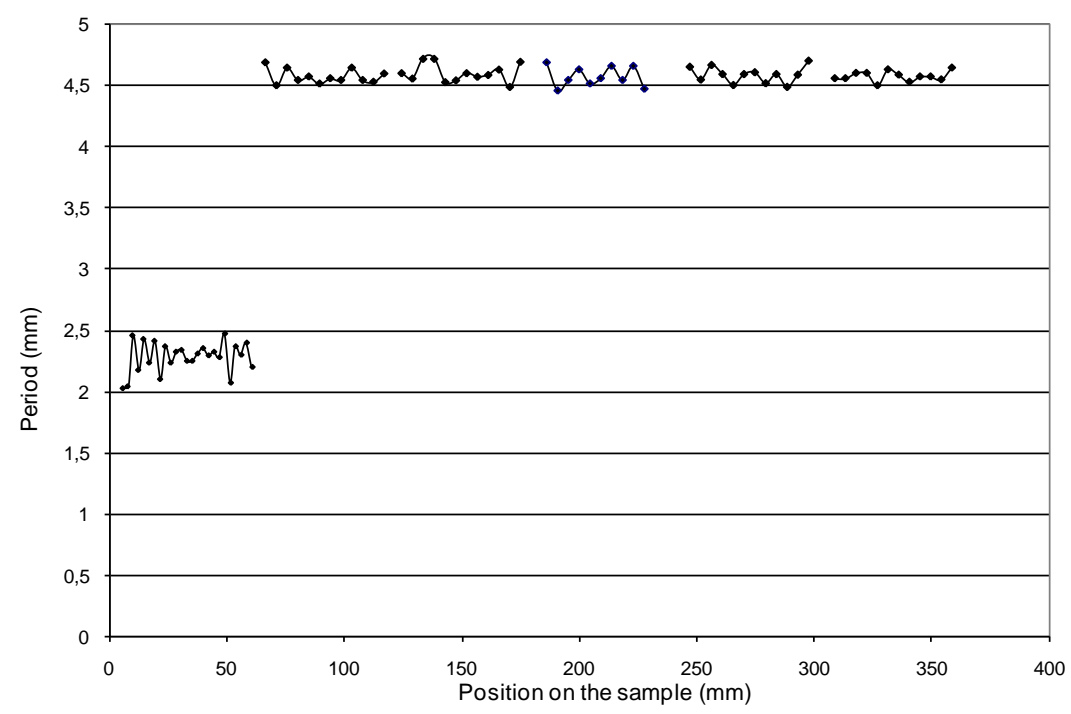


Figure 6: Characteristic periods of the signal in zone A and B in length units for the Glass plain weave1.

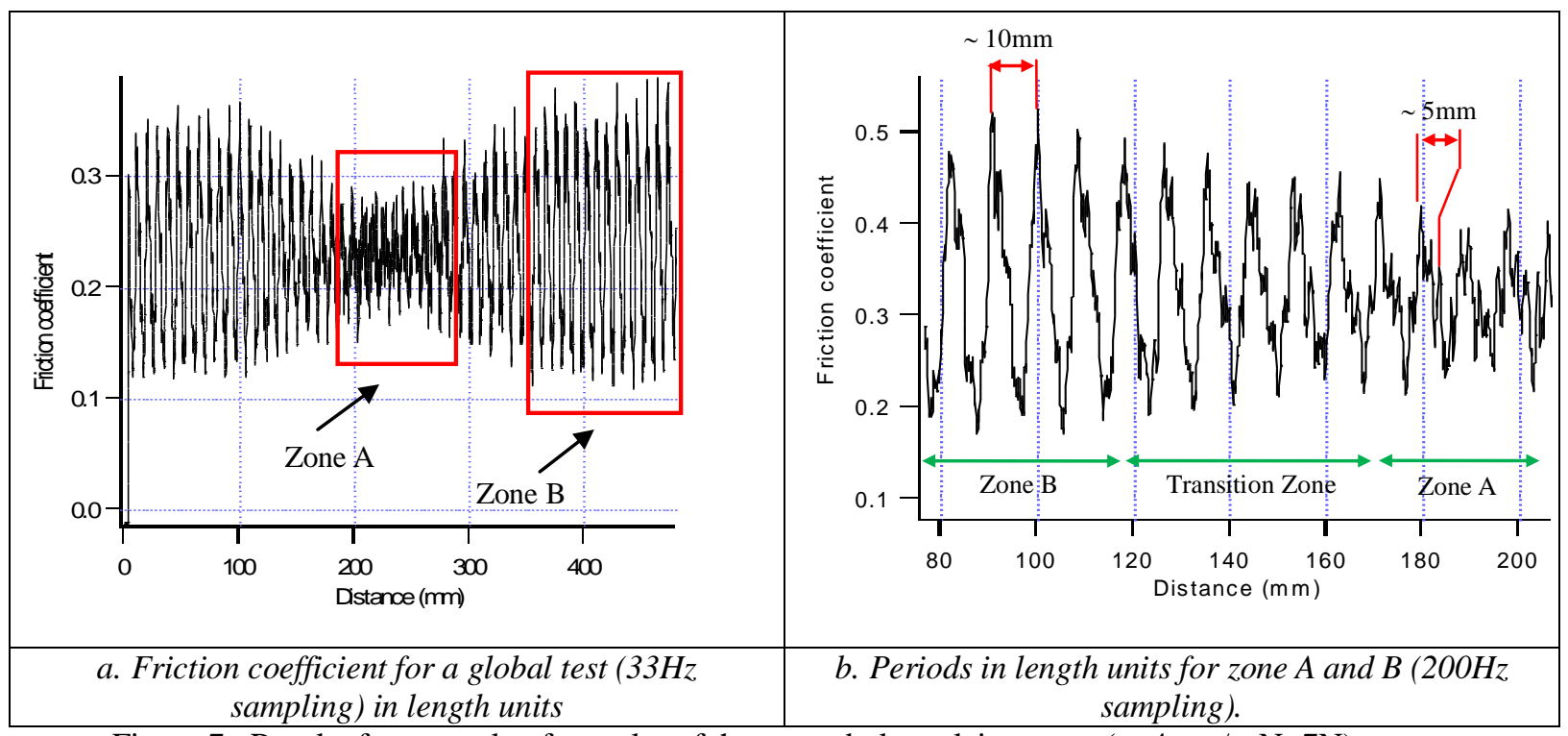

Figure 7 : Results for a couple of samples of the second glass plain weave $(v=4 \mathrm{~mm} / \mathrm{s}, \mathrm{N}=7 \mathrm{~N})$.
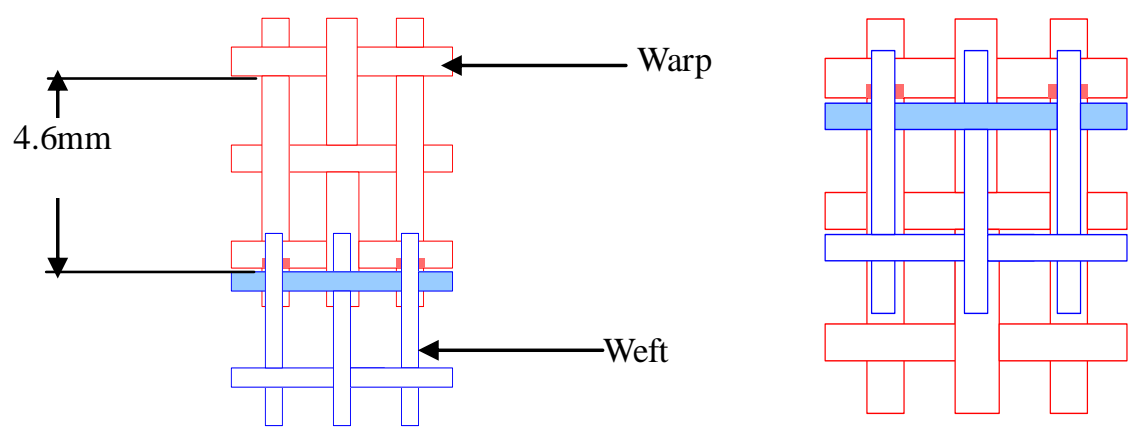

a. Superimposed samples
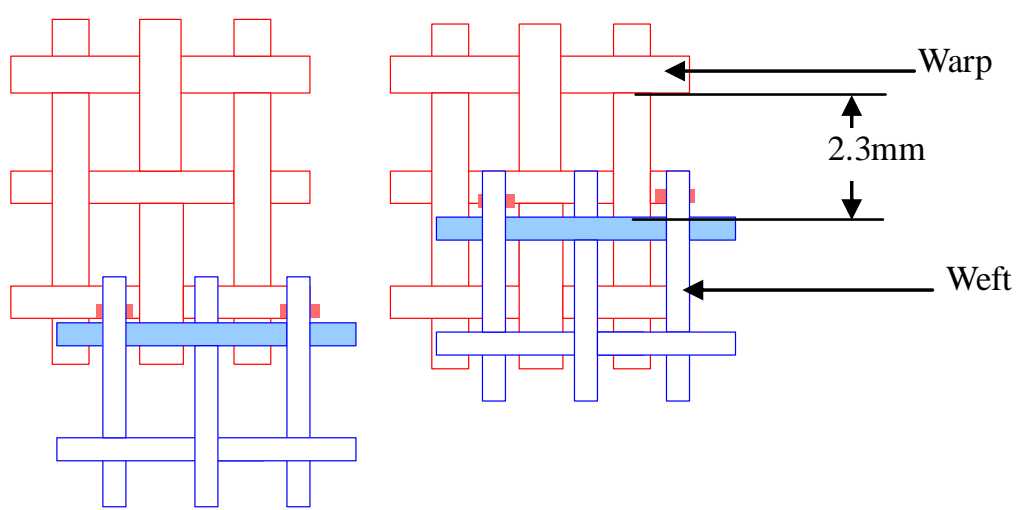

b. Shifted samples

Figure 8: Samples relative lateral positioning 


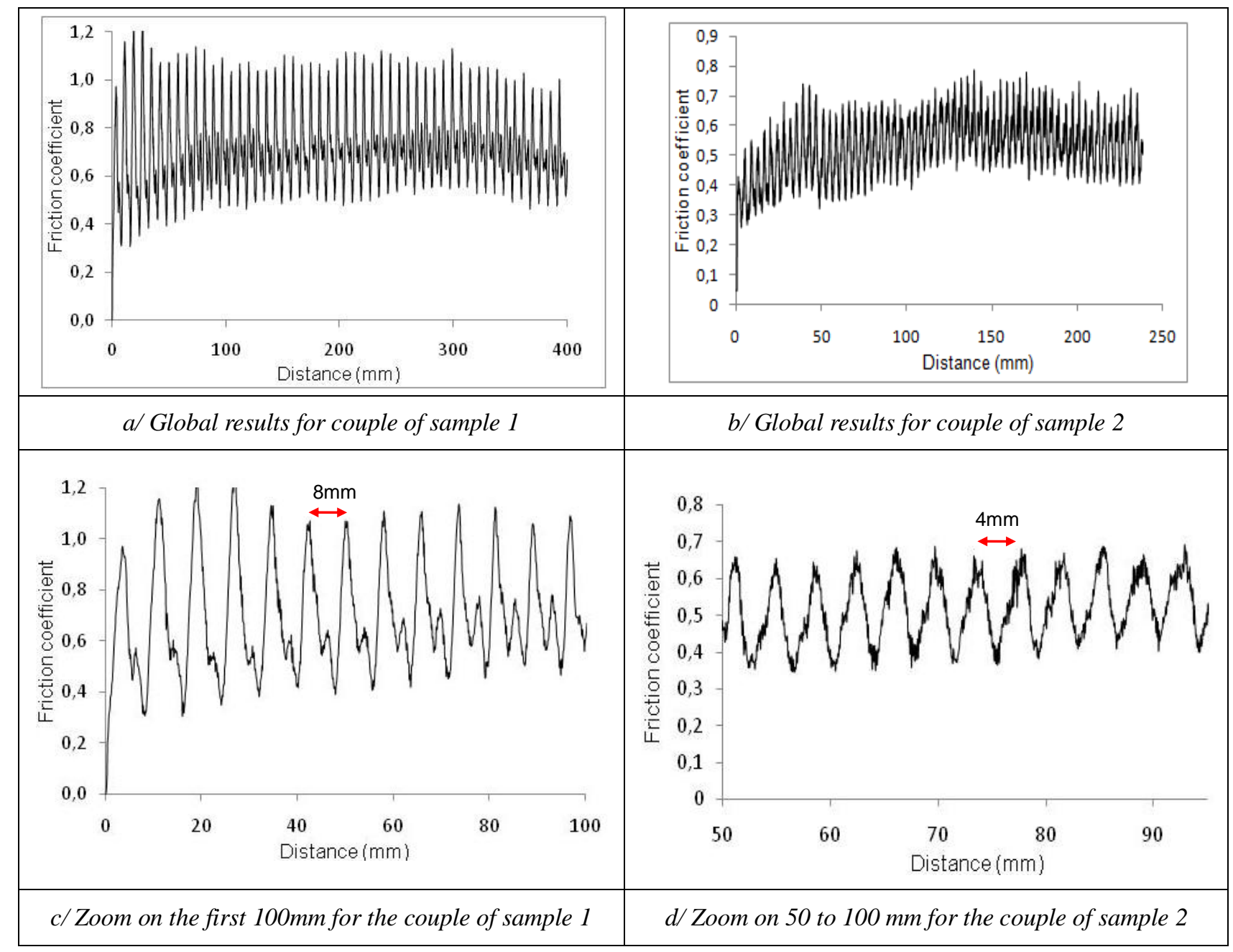

Figure 9 : Friction coefficient as a function of the distance for two couples of interlock fabric samples ( $\mathrm{v}=5 \mathrm{~mm} / \mathrm{s}, \mathrm{N}=10 \mathrm{~N}, 66 \mathrm{~Hz}$ sampling).

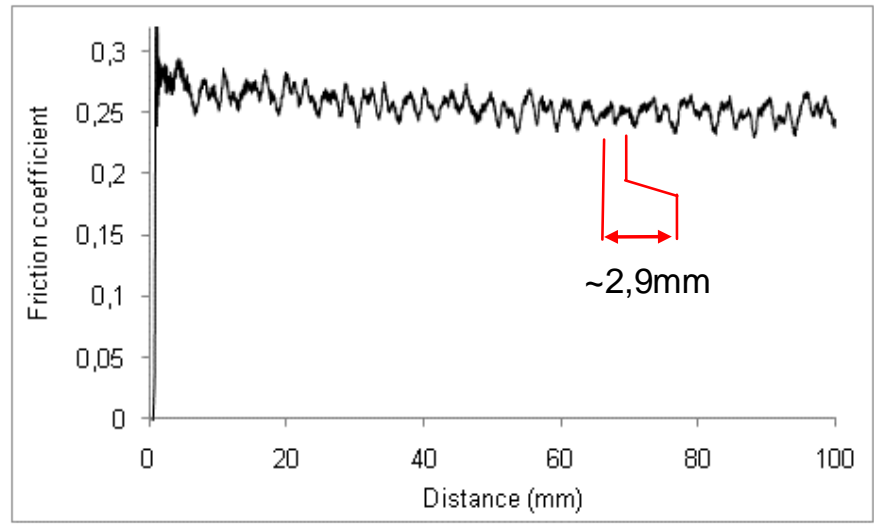

Figure 10 : Friction coefficient as a function of the position on the sample for a twill weave couple of samples ( $=5 \mathrm{~mm} / \mathrm{s}, \mathrm{N}=10 \mathrm{~N}, 200 \mathrm{~Hz}$ sampling). 


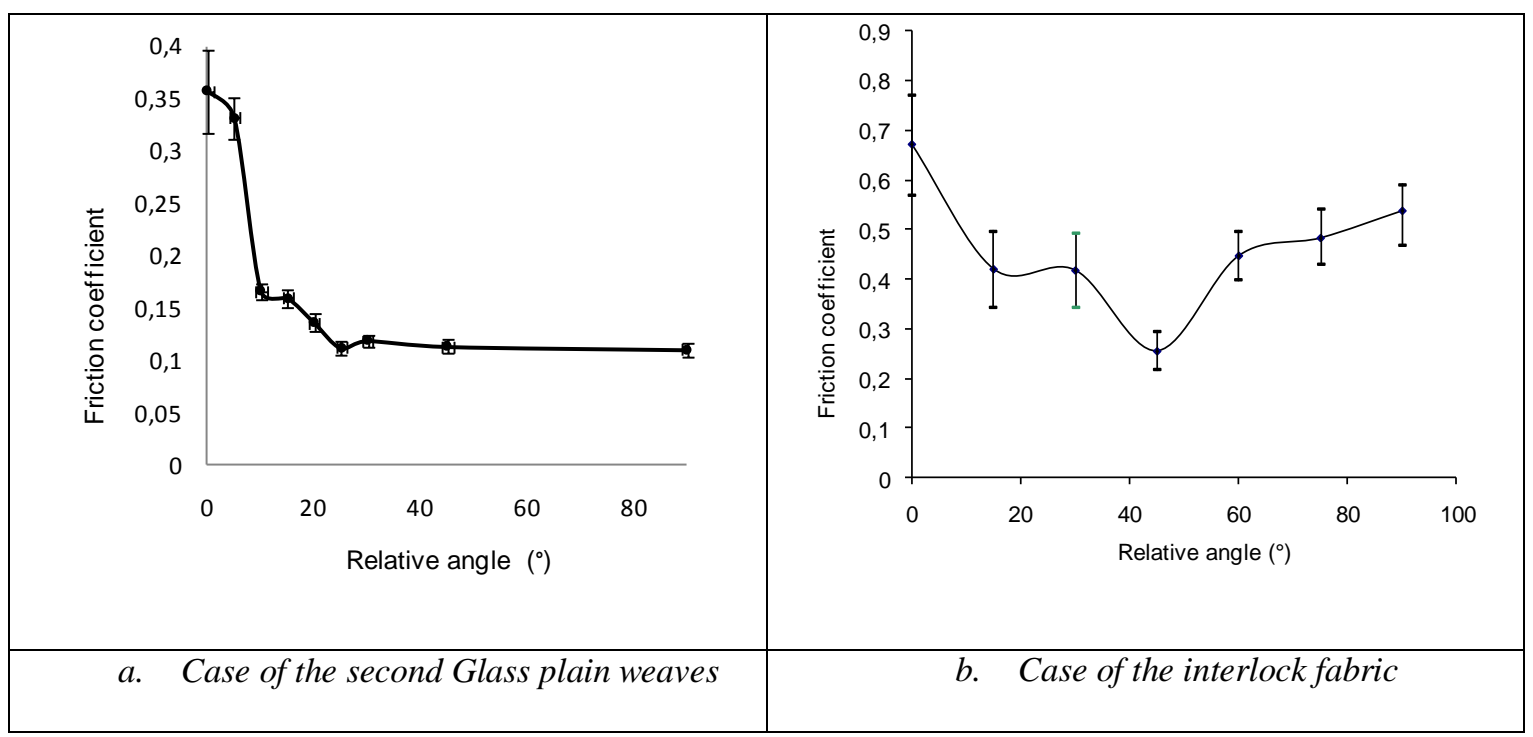

Figure 11 : Average friction coefficient and average standard deviation as a function of the relative orientation between the two samples.

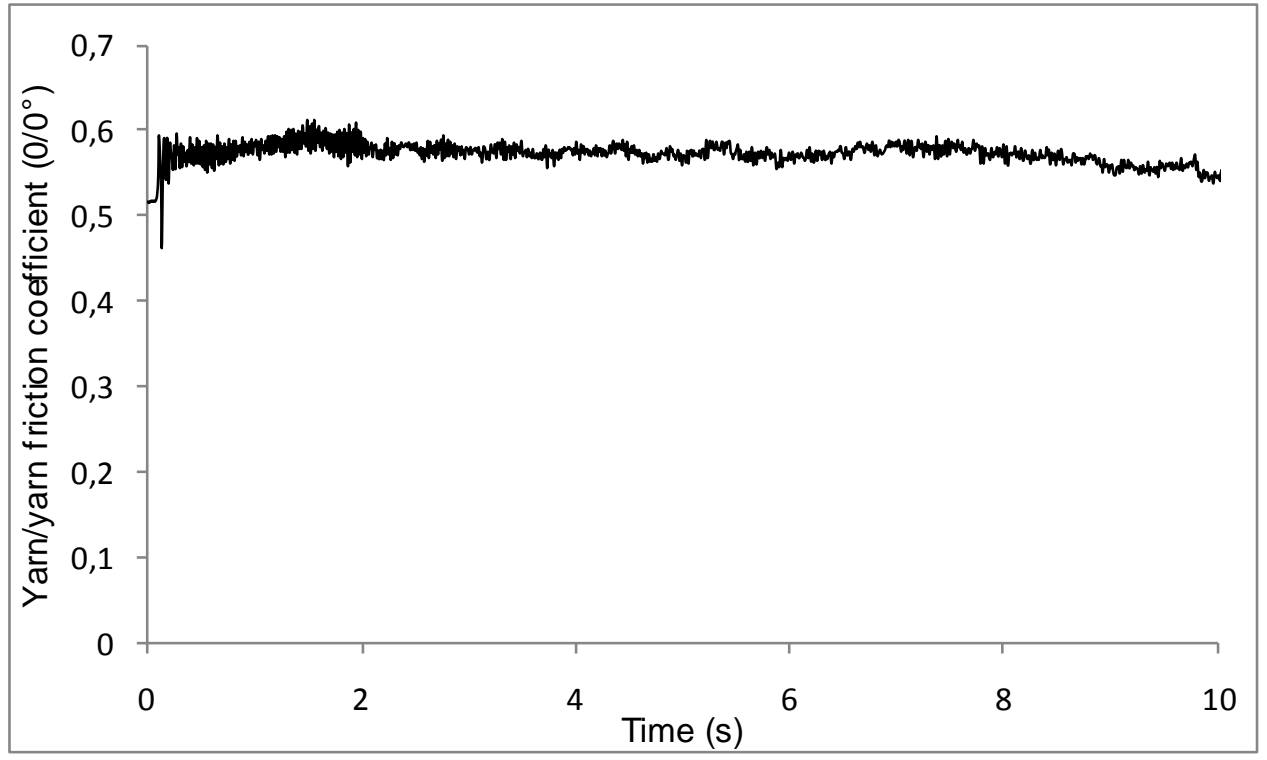

Figure 12: Yarn/yarn $0 / 0^{\circ}$ friction coefficient results for the interlock fabric. 


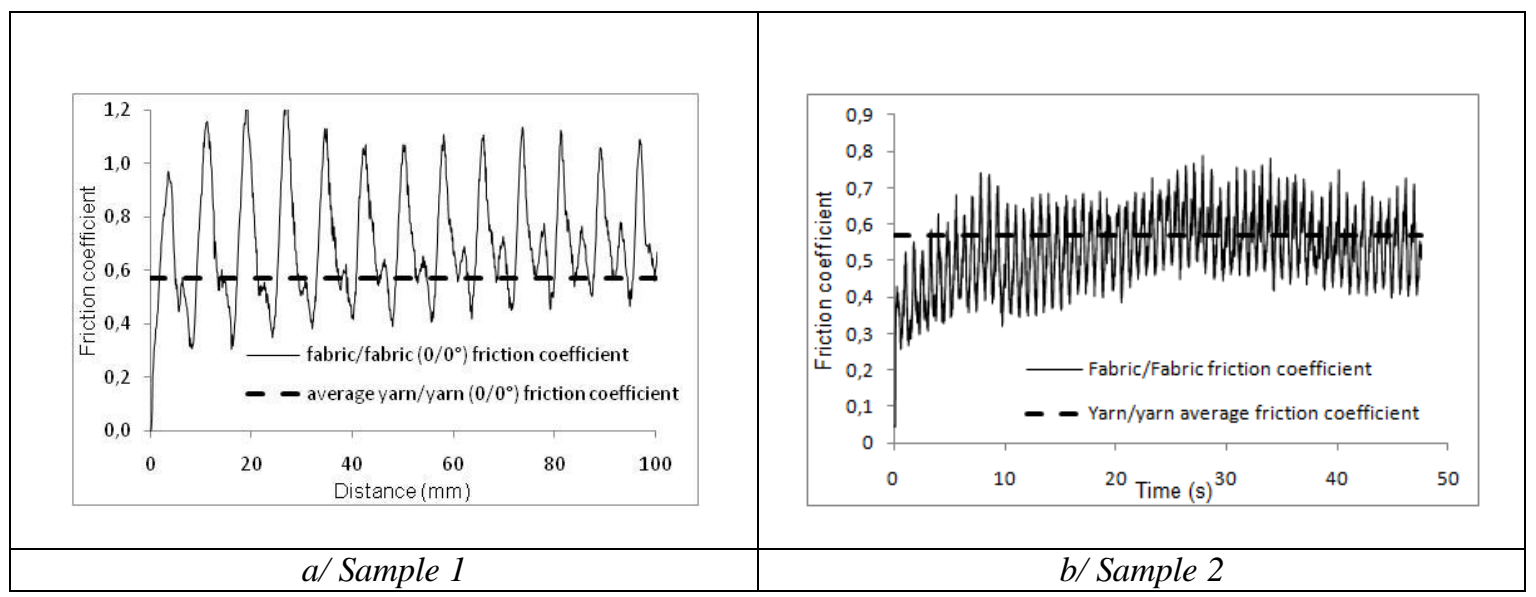

Figure 13: Comparison between yarn/yarn and fabric/fabric friction for the interlock weave with a $0 / 0^{\circ}$ orientation

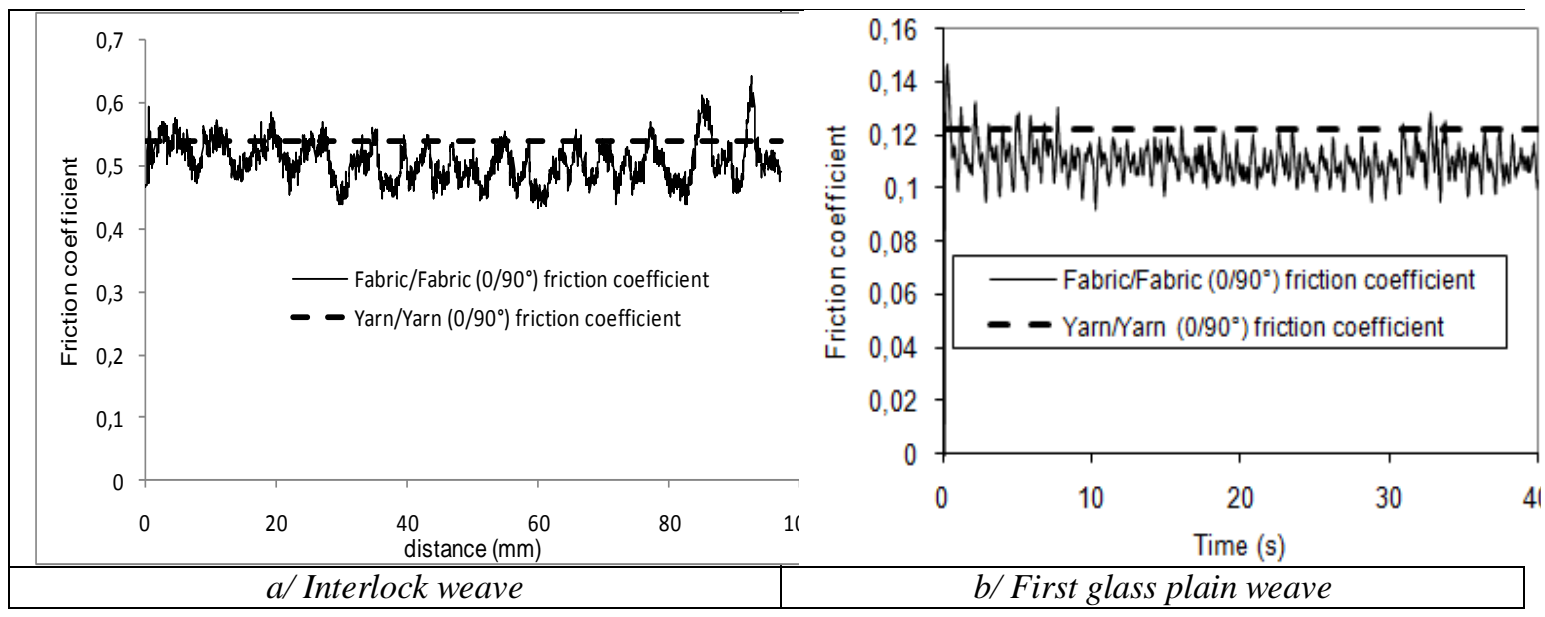

Figure 14: Comparison between yarn/yarn and fabric/fabric friction with $0 / 90^{\circ}$ orientation. 


\begin{tabular}{|c|c|c|}
\hline Yarns & Type & Yarn/yarn friction coefficient \\
\hline \multirow{2}{*}{ Carbon yarns $\left(\mathbf{0}^{\circ} / \mathbf{0}^{\circ}\right)$} & Average & 0,57 \\
\cline { 2 - 3 } & Standard deviation & 0,03 \\
\hline \multirow{2}{*}{ Carbon yarns $\left(\mathbf{0}^{\circ} / \mathbf{9 0}^{\circ}\right)$} & Average & 0,54 \\
\cline { 2 - 3 } & Standard deviation & 0,02 \\
\hline \multirow{2}{*}{ First Glass plain weave yarns $\left(\mathbf{0}^{\circ} / \mathbf{9 0}^{\circ}\right)$} & Average & 0,14 \\
\cline { 2 - 3 } & Standard deviation & 0,01 \\
\hline
\end{tabular}

Table 1: Yarn/yarn average friction coefficient and standard deviation for glass and carbon yarns 